\title{
Pelatihan Digital Marketing sebagai upaya peningkatan Pendapatan Bagi UMKM di kabupaten MBS
}

\author{
Tyahya Whisnu Hendratni \\ Fakultas Ekonomi dan Bisnis, Universitas Pancasila \\ Jakarta, Indonesia
}

\begin{abstract}
This community service activity aims to increase understanding of digital marketing for MSMEs in the MBS district. By maximizing the use of online media, it can increase business competitiveness. For MSME players, adequate online media knowledge and quality content can be used to market their products. This situation is very influential, significantly since the Covid 19 pandemic that has hit Indonesia since March 2020 has changed the way people meet their daily needs. Consumers who used to shop directly are now experiencing changes by using digital transactions. Marketing online through social media provides opportunities for MSME to interact with consumers. The approach method used is for active MSMEs. The method is done by providing counseling online through zoom media. This service activity was carried out orderly and smoothly. The participants were very enthusiastic about listening to the speakers' presentations. The attendance of the participants proves this right from the beginning of the event to the end of the event. It is hoped that training and the service team can assist MSMEs so that they can monitor the progress of increasing sales turnover.
\end{abstract}

Keywords

Digital Marketing, Increase in UMKM income, Training Via Zoom

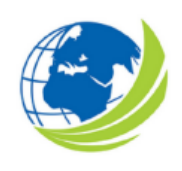

BERDAYA : Jurnal Pendidikan dan Pengabdian Kepada Masyarakat Vol 3, No.2, Agustus 2021, pp. $59-66$ eISSN 2721-6381

\section{Article History}

Received 25 May 2021 / Accepted 25 Aug 2021 / First Published: 31 Aug 2021

To cite this article

Hendratni, T. (2021). Pelatihan Digital Marketing sebagai upaya peningkatan Pendapatan Bagi UMKM di kabupaten MBS. BERDAYA: Jurnal Pendidikan Dan Pengabdian Kepada Masyarakat, 3(2), 59 - 66

DOI: $10.36407 /$ berdaya.v3i2.348

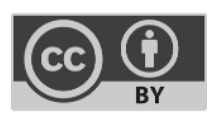

(C) The Author(s)2021

. This open access article is distributed under a Creative Commons Attribution (CC-BY) 4.0 license 
ABSTRAK

Profil Penulis

Kegiatan pengabdian masyarakat ini bertujuan untuk meningkatkan pemahaman digital marketing bagi UMKM di wilayah MBS. Dengan memaksimalkan penggunaan media online dapat meningkatkan daya saing bisnis. Bagi pelaku UMKM, pengetahuan media online yang memadai dan konten yang berkualitas dapat digunakan untuk memasarkan produknya. Situasi ini sangat berpengaruh, signifikan sejak pandemi Covid 19 yang melanda Indonesia sejak Maret 2020 telah mengubah cara masyarakat memenuhi kebutuhan sehari-hari. Konsumen yang dulunya berbelanja langsung kini mengalami perubahan dengan menggunakan transaksi digital. Pemasaran online melalui media sosial memberikan peluang bagi UMKM untuk berinteraksi dengan konsumen. Metode pendekatan yang digunakan adalah untuk UMKM aktif. Metode dilakukan dengan memberikan penyuluhan secara online melalui media zoom. Kegiatan pengabdian ini dilaksanakan dengan tertib dan lancar. Para peserta sangat antusias mendengarkan pemaparan pembicara. Kehadiran peserta membuktikan hal tersebut sejak awal acara hingga akhir acara. Diharapkan pelatihan dan tim pengabdian dapat membantu UMKM agar dapat memantau perkembangan peningkatan omzet penjualan.

Kata Kunci : Digital Marketing, Increase in UMKM income, Training Via Zoom
Tyahya Whisnu Hendratni

Fakultas Ekonomi dan Bisnis,

Universitas Pancasila

Jakarta, Indonesia

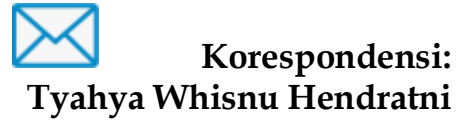

email:

tyahyawhisnu@univpancasila.ac.id

Reviewing Editor

Hendryadi, STIE Indonesia

\section{PENDAHULUAN}

Perubahan perkembangan zaman dari waktu ke waktu, pasar mengalami evolusi bentuk tempat dan cara mengelolanya. Teknologi Informasi mengalami revolusi. Pemasaran dalam beberapa tahun terakhir mengalami perubahan ( Ascharisa Mettasatya Afrilia , 2018). Terjadi perubahan dari yang bersifat tradisional menjadi modern. Selain itu juga, masyarakat mengalami perubahan pemilihan tempat untuk membeli kebutuhan sehari-hari yakni terjadi pergeseran dari tradisional menjadi modern. Di masa pandemic Covid 19 terjadi perubahan pola belanja konsumen di mana konsumen semakin jarang terlihat berinteraksi langsung terhadap produsen atau penjual dalam memenuhi kebutuhannya. Pemasaran yang dilakukan secara online lewat social media memberikan kesempatan bagi UMKM atau produsen untuk berinteraksi dengan konsumen. UMKM dapat berinteraksi dengan calon pembeli dan dapat mempengaruhi para calon pembeli tersebut untuk melihat dan mempelajari produk UMKM dan kemudian membelinya. Mengingat begitu pentingnya digital marketing bagi UMKM di kabupaten MBS maka diadakanlah pelatihan Digital Marketing sebagai upaya peningkatan Pendapatan Bagi UMKM. 
Luaran yang diharapkan dari pelatihan ini adalah : (1) Sasaran kepesertaan dari kegiatan pengabdian ini adalah para pelaku UMKM yang aktif dikabupaten MBS (2) Dapat meningkatkan kemampuan para pelaku UMKM dalam digital marketing sehingga memudahkan dalam memasarkan produk-produknya(3) Modul ( Buku panduan ) dalam melakukan digital marketing yang bisa digunakan oleh UMKM, dinas-dinas terkait dan masyarakat secara luas.

\section{Sasaran Kegiatan}

Kegiatan pengabdian kepada masyarakat (PKM) ini merupakan kegiatan yang bertujuan untuk meningkatkan pemahaman dan penggunaan dalam melakukan digital marketing di kabupaten MBS sehingga usaha yang dilakukan dapat lebih maju dan lebih berkembang lagi.

\section{Masalah yang ingin dipecahkan:}

Pada dasarnya perusahaan atau pelaku usaha dalam melakukan kegiatan usahanya pastinya berkeinginan untuk membuat produknya laku terjual. Dalam hal ini, perusahaan akan menghadapi persaingan yang ketat, sehingga perlu melakukan strategi pemasaran yang tepat. Menurut Kotler dan Keller (2012) pemasaran merupakan kegiatan yang bertujuan untuk menciptakan pasar. Strategi Pemasaran atau bauran pemasaran (Marketing Mix) meliputi : Product, Price, Place, Promotion. Contoh strategi pemasaran konvensional yang diterapkan dari dulu hingga sekarang misalnya iklan, direct marketing, dan sales promotion. Ketiga contoh tersebut bukannya tidak digunakan di masa sekarang, tetapi sebaiknya perusahaan (produsen) tentunya perlu mempertimbangkan media yang lain dan strategi pemasaran yang lebih sesuai .

Potensi pasar online di Indonesia seharusnya dimaksimalkan oleh para UMKM untuk meningkatkan penjualan. Terutama di masa pandemi , di mana berbagai upaya penanganan penyebaran covid, seperti physical distancing dan PSBB dan membatasi aktivitas jual beli di pasar offline. Dibandingkan dengan pasar offline, penjualan melalui pasar online memiliki sejumlah kelebihan. (1) Memudahkan pelaku usaha menjangkau pasar yang lebih luas. (2) Memudahkan menjalin komunikasi dengan pelanggan (3) Mampu menjangkau target pasar yang spesifik. Permasalahannya potensi manfaat ekonomi dari pasar online belum sepenuhnya mampu dioptimalkan karea rendahnya kemampuan teknologi dan digital para pelaku UMKM. Data Kementerian Koperasi dan UKM menunjukkan baru 17\% dari UMKM atau sekitar 11 juta dari total 64 juta UMKM yang sudah go online. Dari 11 juta yang sudah go online ini, 3 juta diantaranya adalah pelaku UMKM yang baru memanfaatkan pasar digital pada masa pandemi.

\section{MATERI DAN METODE}

\section{Materi}

Pengguna jaringan internet dan teknologi di Indonesia sangat tinggi. Berdasarkan data Review Global Digital diketahui pengguna handphone adalah 338.2 juta di Indonesia sementara pengguna internet aktif yaitu 175.4 juta dan pengguna sosial media adalah 160 juta. Terlihat bahwa pasar online potensi pasarnya sangat besar. UMKM merupakan sektor usaha yang paling berpeluang dalam meningkatkan penjualan karena di masa pandemi, untuk meminimalisir penyebaran covid maka Pemerintah membuat kebijakkan seperti : PSBB ( Pembatasan Sosial Berskala Besar), physical distancing (Pembatasan Fisik) dan transaksi Jual beli secara offline juga dibatasi. 
Hal-hal yang harus diperhatikan para produsen atau pelaku usaha dalam melakukan digital marketing antara lain : (1) Melakukan analisa persaingan produk dan harga pasar (2) pengecekan sosial media (3) sosial media yang dipilih yaitu yang mempunyai nilai keamanan yang tinggi (4)produk di upload di sosial media (5) Melakukan transaksi pembukuan secara reguler, merespons dan mengawasi percakapan (6) Memiliki rekening bank dan siap menerima pesanan (7) Buat konten promosi yang menarik dan pilih cara pengiriman barang yang paling sesuai.

Tim Pengabdian kami sangat berkeinginan untuk mengedukasi dan memfasilitasi UMKM agar dapat menggunakan media sosial secara maksimal sehingga omzet pendapatan yang diperoleh dapat meningkat.

\section{Analisis Instagram marketing}

Ada perubahan perilaku konsumen saat ini, dimana 84\% konsumen membeli barang karena medsos ( Facebook, Twitter, Instagram, Youtube dan LINE ). UMKM sangat diharapkan untuk bisa memanfaatkan medsos untuk meningkatkan kinerja penjualan produknya. Dengan memanfaatkan sosmed maka hambatan jarak, ruang dan waktu serta harga barang bisa diminimalisir. Jarak tidak menjadi hambatan untuk mengirim barang, karena sudah banyak perusahaan jasa pengiriman untuk mengantar barang dengan harga murah dan bisa cepat sampai tujuan. Jangkauan pemasaran pun bisa mendunia. Oleh karenanya diharapkan para UMKM sudah mulai mempromosikan atau berjualan produk melalui medsos. Hal-hal yang perlu diketahui UMKM dalam menggunakan media sosial : (1). Sikap dan perilaku harus dijaga (2)Membuat network (3) Ada peluang usaha(4) Ada skill yang harus dimiliki. Selain itu ciptakan brand dan merek produk yang mudah diingat.

Media sosial yang paling popular adalah Instagram. Yang terpenting dari Instagram bukan hanya memposting video atau gambar saja tetapi diperlukan strategi agar bisnis bisa menjangkau seluruh pengguna Instagram. Instagram lebih ditujukan untuk konten dimana pengguna lebih menyukai konten yang baru dan up dated. Strategi Pemasaran Instagram untuk meningkatkan penjualan dapat dilakukan dengan cara sebagai berikut : (1) Membuat komunitas lewat Hasthtag sehingga video atau foto dapat dilihat oleh banyak orang (2) Kesesuaian follower dan trend bisnis (3) Memakai fitur Instagram (4) Interaksi dengan pelanggan(5) Menggunakan visual yang konsisten sehingga dikenal oleh follower (6) Subjek yang ditampilkan dapat menambah followernya.

\section{Pelaksanaan Kegiatan}

\section{HASIL DAN PEMBAHASAN}

Berikut adalah hasil dan pembahasan mengenai pembahasan pelaksanaan kegiatan Pengabdian kepada Masyarakat.

\section{Kegiatan Awal :}

Pengabdian Kepada Masyarakat dilakukan pada akhir Bulan Januari tahun 2021. Kegiatan kerjasama dengan Kabupaten MBS diawali dengan komunikasi via telepon dengan Dinas Pemberdayaan Masyarakat dan Desa Kabupaten MBS. Mengingat pada bulan Januari 2021 covid masih sangat tinggi maka seluruh aktivitas pengabdian dilakukan secara daring menggunakan Zoom. Setelah itu, Dinas terkait mengirimkan data sejumlah peserta yang akan mengikuti pelatihan, yaitu terdapat 25 pelaku usaha yang terdiri dari 5 ( lima ) UMKM dan 20 BUMDES dengan berbagai bentuk usaha seperti usaha fotocopy, agen gas, penyewaan , mini market, warung sembako dan lain-lain. Demi ketertiban peserta pelatihan 
diberikan angket persetujuan untuk mengikuti acara secara penuh sehingga pemahaman materi pelatihan lebih maksimal.

\section{Kegiatan Inti :}

Kegiatan Pengabdian Kepada masyarakat dilakukan secara daring melalui media ZOOM. Untuk mempermudah komunikasi dibuatlah grup whatsapp . Pada Gambar 1 terlihat sesi foto bersama peserta pelatihan. Masa Pandemi covid tidak menghilangkan semangat untuk mendapatkan ilmu yang luar biasa terkait pemasaran yang dilakukan secara online.
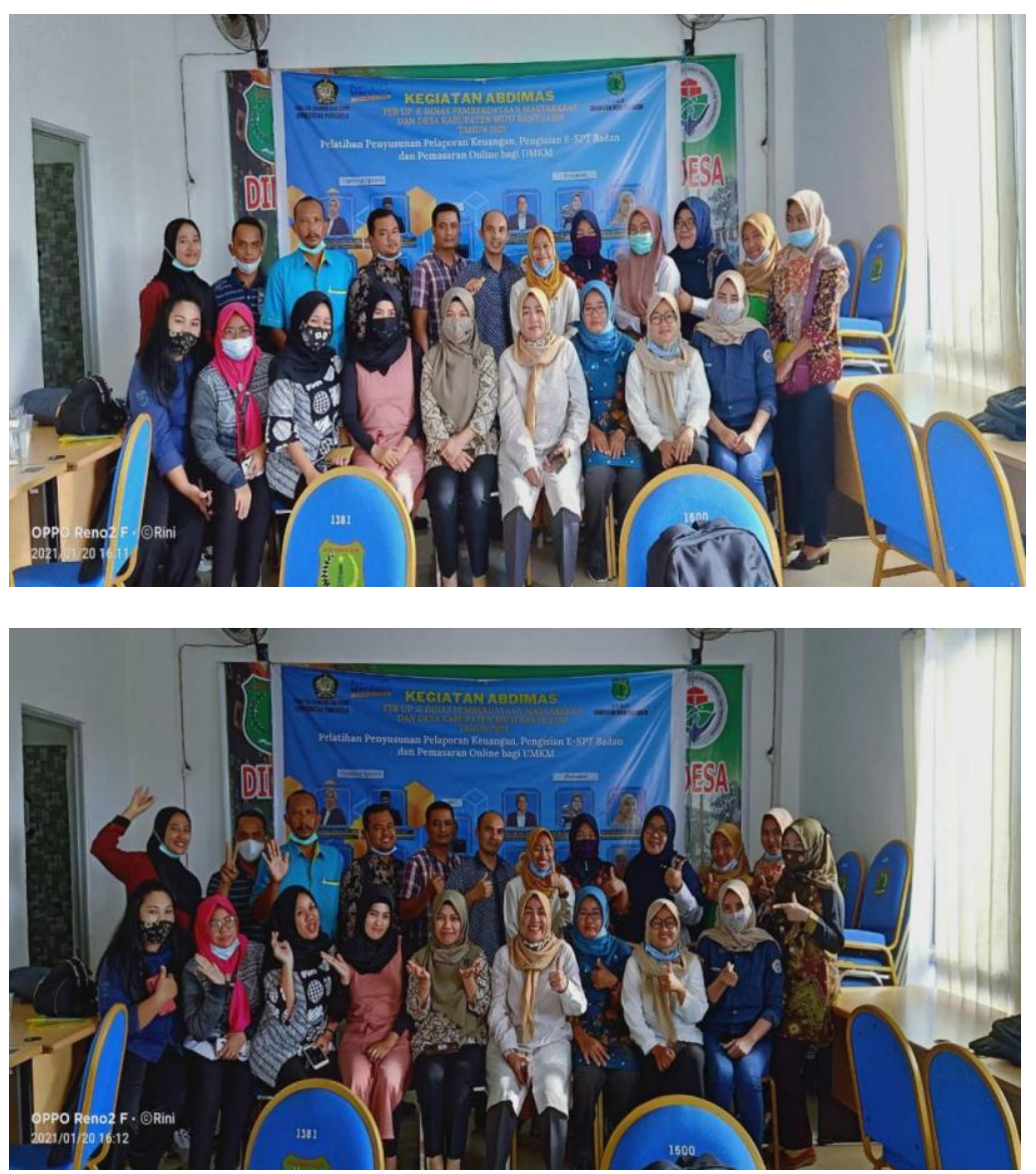

Gambar 1.

Gaya Bebas Peserta Pelatihan

Sumber:

dokumentasi tim di lapangan

Tim Fasilitator adalah para dosen yang bertugas dan mempunyai peran yang sangat aktif dalam menjawab pertanyaan dan melakukan pendampingan selama pelatihan. Rundown acara sebagai berikut :

Tabel 1.

Jadwal Kegiatan

\begin{tabular}{lll}
\hline WAKTU & KEGIATAN & PELAKSANA \\
\hline $12.00-13.00$ & ISHOMA dan Registrasi Ulang & UMKM dan Tim Pengabdian \\
$13.00-13.15$ & Ice Breaker Moderator & Tim Pengabdian \\
$13.15-13.40$ & Digital Marketing & Tim Pengabdian \\
$13.45-14.30$ & Materi Tentang Instagram & Tim Pengabdian \\
$14.30-15.00$ & Tanya Jawab & Tim Pengabdian \\
\hline
\end{tabular}



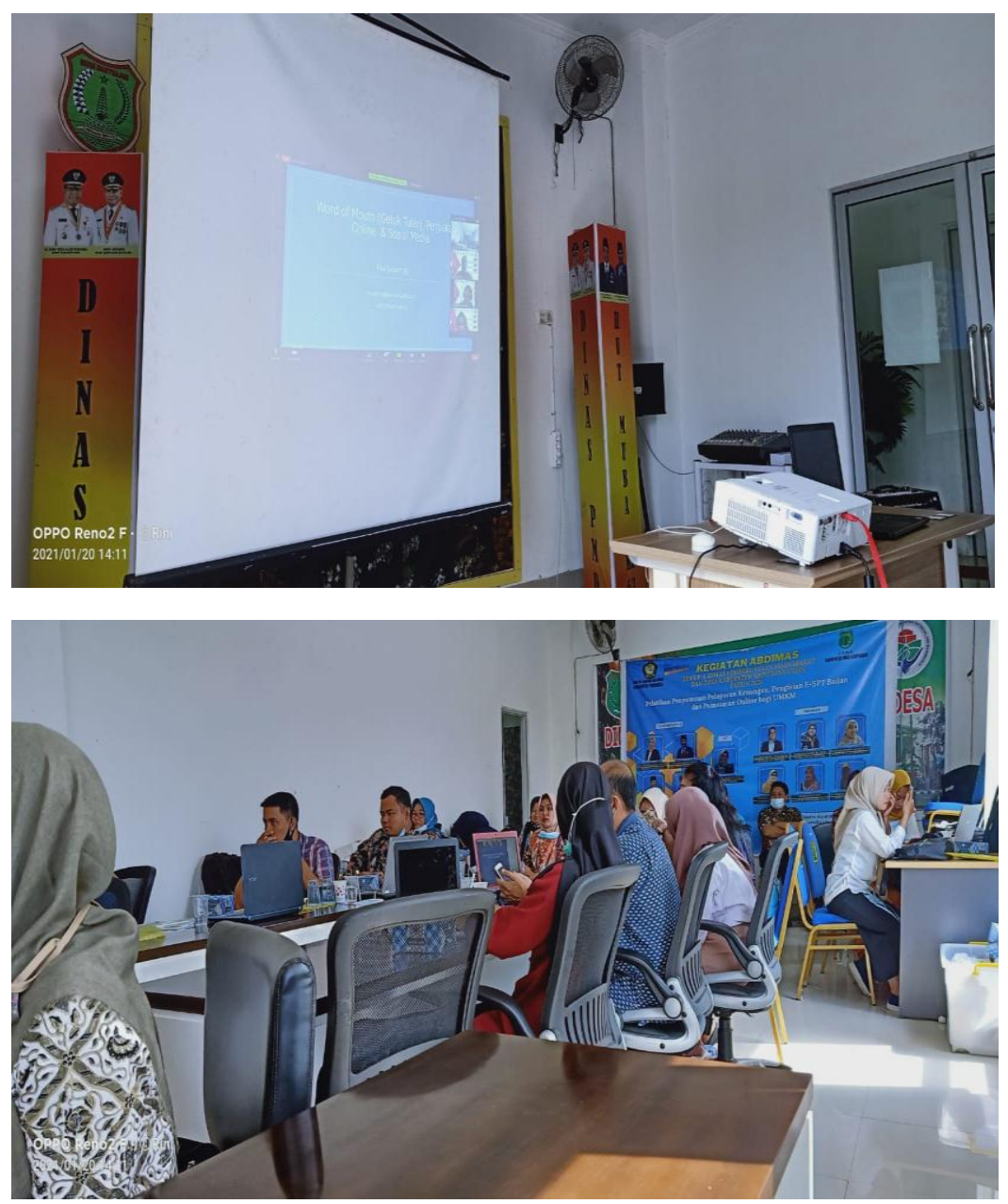

Gambar 2.

Pelaksanaan Kegiatan

Sumber:

dokumentasi tim di lapangan

Pada Gambar 2 terlihat bahwa para peserta sangat antusias dan serius dalam mendengarkan Pemaparan dari para naarasumber. Dan semua terlihat langsung mempraktekkan apa yang sedang Diajarkan oleh tim Pengabdian .

\section{KESIMPULAN}

Secara umum peserta pelatihan: (a) UMKM sangat berkeinginan dan berminat dalam mempraktekkan materi pelatihan; (b) Media Sosial dan Digital Marketing memudahkan UMKM untuk inovasi produk dan penjualan produk; (c) setelah mengikuti pelatihan , para peserta mendapatkan ilmu dan pengetahuan mengenai konsep dan aplikasi digital marketing sehingga dapat langsung digunakan dalam memasarkan produk mereka.

\section{Saran Kegiatan lanjutan}

Secara keseluruhan kegiatan pelatihan ini berjalan lancar dan tertib. Kedepannya sangat diharapkan bukan saja berhenti sampai dengan tahap pelatihan saja tetapi para UMKM masih perlu pendampingan dalam memasarkan produk-produknya melalui pemasaran online. Para peserta sangat berharap sekali pelatihan terkait pemasaran online lebih sering diadakan lagi. 


\section{REFERENSI}

Ascharisa mettastya Afrilia. (2018). Digital Marketing sebagai strategi komunikasi. Jurkom, Riset Komunikasi, 1(1), 147-157

Cant, M.C \& Wild, J.A (2016). The use of traditional marketing tools by SMEs in an emerging economy: a South African perspective in Management, Volume 14, issue 1, 2016

Charlesworth, A. (2014). Digital marketing : A practical approach. Routledge.

Morris, N. (2009). Understanding digital markrting ; marketingstrategies for engaging the digital generation.

Kotler, Philip and Keller Kevin Lane. 2012. Principles of Marketing : 14 th Edition. Prentice Hall. New Jersey.

Setiawati, I., \& Widyartati, P. (2017). Pengaruh Strategi Pemasaran Online Terhadap Peningkatan Laba UMKM. In Proceedings. Vol.1 (1) 
About Author

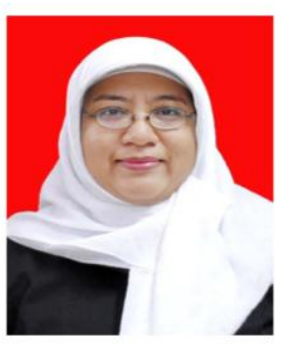

Tyahya Whisnu Hendratni adalah Dosen Tetap pada Fakultas

Ekonomi dan Bisnis Universitas Pancasila. Penulis dapat dihubungi di alamat email: tyahyawhisnu@univpancasila.ac.id

\section{Declarations}

\section{Funding}

Kegiatan ini merupakan bagian dari program Pengabdian Kepada Masyarakat yang didanai oleh Fakultas Ekonomi dan Bisnis, Universitas Pancasila.

\section{Competing Interests}

Tidak ada konflik kepentingan untuk diungkapkan. 